\title{
Uso de FTIR-ATR Na Caracterização da Curdulana e Na Avaliação da Interação Entre Células de Agrobacterium Sp. IFO 13140 e a Matriz de Imobilização Esponja Vegetal
}

Camila Ortiz Martinez (I), Vanderson Carvalho Fenelon (I), Suelen Pereira Ruiz (I), Gutierrez Rodrigues de Morais (I), Mauro Luciano Baesso (I), Graciette Matioli (I)

(I) UEM - Universidade Estadual de Maringá (Av. Colombo , 5.790. CEP: 87020-900, Maringá, $\mathrm{PR}, \mathrm{BR})$

\section{Resumo}

Curdulana é um exopolissacarídeo neutro, linear e composto exclusivamente por unidades de glicose ligadas por ligações do tipo $\beta$ $(1,3)$. Suas propriedades térmicas e reológicas são únicas e tem permitido a sua aplicação para melhorar a textura, a retenção de água e a estabilidade térmica de diversos alimentos. Células de Agrobacterium sp. IFO 13140 imobilizadas em esponja vegetal foram empregadas na produção de curdulana durante cinco ciclos sucessivos. Foram obtidas micrografias de células livres e imobilizadas do microrganismo em um microscópio eletrônico de varredura. Espectrometria de infravermelho por transformada de Fourier (FTIR-ATR) foi utilizada na caracterização da curdulana, e na avaliação da interação entre as células microbianas e a matriz esponja vegetal nos primeiro, segundo e terceiro ciclos de produção de curdulana. Foi avaliada a pureza da curdulana produzida pelo microrganismo. A estabilidade de armazenamento das células imobilizadas também foi avaliada durante 300 dias de estocagem a $-18^{\circ} \mathrm{C}$. Grande número de células aderiram fisicamente a superfície das fibras da esponja vegetal e mantiveram o seu metabolismo e consequente produção de curdulana que foi de 17,84 g/L, valor médio obtido no decorrer de cinco ciclos sucessivos de cultivo. A presença do microrganismo na esponja foi evidenciada pelo

\footnotetext{
Referência:

Camila Ortiz Martinez, Vanderson Carvalho Fenelon, Suelen Pereira Ruiz, Gutierrez Rodrigues de Morais, Mauro Luciano Baesso, Graciette Matioli.Uso de Ftir-Atr Na Caracterização da Curdulana e Na Avaliação da Interação Entre Células de Agrobacterium Sp. Ifo 13140 e A Matriz de Imobilização Esponja Vegetal. In: Anais do 12 Congresso Latinoamericano de Microbiologia e Higiene de Alimentos - MICROAL 2014 [= Blucher Food Science Proceedings, num.1, vol.1]. São Paulo: Editora Blucher, 2014. DOI 10.5151/foodsci-microal-037
} 
aparecimento da banda de transmitância em 1080 cm-1, no espectro obtido por FTIR-ATR, e não provocou alterações na esponja, confirmando a eficácia da sua aplicação como matriz de imobilização. As células imobilizadas do microrganismo apresentaram elevada estabilidade após 300 dias de armazenamento. A curdulana produzida apresentou a mesma estrutura molecular da curdulana comercial, conforme o espectro obtido por FTIR-ATR, e pureza similar, de 87,41\%. Os resultados demonstram a possibilidade da imobilização de células de Agrobacterium sp. IFO 13140 na matriz esponja vegetal para a produção de curdulana.

Palavras-Chave: Agrobacterium sp., curdulana, esponja vegetal, imobilização, FTIR-ATR

Agência de Fomento: Coordenação de Aperfeiçoamento de Pessoal de Nível Superior (CAPES), Conselho de Desenvolvimento Científico e Tecnológico (CNPQ) e Fundação Araucária 